\title{
Upaya Peningkatan Pendapatan Industri Kecil Menengah Dengan Pembuatan Toko Daring Berbasis Framework Codeigniter
}

\author{
Very Kurnia Bakti ${ }^{1}$, Arif Rakhman ${ }^{2}$ \\ ${ }^{1}$ Program Studi D3 Teknik Komputer, Politeknik Harapan Bersama \\ Jl. Mataram No.9, Tegal 52147, e-mail: verykurniabakti@poltektegal.ac.id \\ ${ }^{2}$ Program Studi D3 Teknik Komputer, Politeknik Harapan Bersama \\ Jl. Mataram No.9, Tegal 52147, e-mail: arif.rahman@poltektegal.ac.id
}

\section{ARTICLE INFO}

Article history:

Received 23 July 2018

Received in revised form 30 July 2018

Accepted 3 Agustus 2018

Available online 17 Agustus 2018

\begin{abstract}
Based on some Small and Medium Industries (IKM) in Tegal City, almost all products from Small and Medium Industries (IKM) are marketed through classical transactions or conventional transaction models. There are still many producers who have not been able to promote and market their products online due to the absence online store facilities toward Small and Medium Industries (IKM) of Tegal City and the limited knowledge level of business managers about the utilization of information technology. Research will be conducted through several stages. Initial stages by collecting data - data from Small and Medium Industries (IKM) principal participants such as photos of its product, price lists, product specifications and others. Next stages is to do an analysis of the data the data by selecting products - products that are allowed to be sold by online. Later stages is to design and build online store website pages to be uploaded and accessed via internet which will be the place for promotion and sales of Small and Medium Industries (IKM) products in Tegal City by online. The output product of this research will be one of the efforts in helping to increase the Small and Medium Industries (IKM) income of Tegal City
\end{abstract}

Keywords: Online shop, Small and Medium Industries (IKM), Tegal city

\section{Introduction}

Pada sesi diskusi dengan para CEO perusahaan di bidang TI dalam Konferensi Tingkat Tinggi (KTT) ASEAN-AS di California. Presiden Indonesia Joko Widodo menyampaikan pandangannya mengenai teknologi dan ekonomi digital yang harus membawa manfaat untuk rakyat, khususnya Industri Kecil dan Menengah (IKM) di Indonesia. IKM harus mendapat akses terhadap teknologi dan ekonomi digital Indonesia. Pemerintah memiliki visi untuk menjadikan Indonesia sebagai digital ekonomi terbesar pada tahun 2020. Indonesia telah meluncurkan Roadmap E-commerce Nasional yang merupakan hasil kolaborasi delapan kementerian dengan nilai 130 miliar dolar AS dan menciptakan 1.000 tecnopreneurs dengan nilai bisnis 10 miliar 
dolar AS pada tahun 2020. "Ini adalah langkah langkah besar untuk mendorong inovasi teknologi sehingga bermanfaat bagi rakyat" [1] .

Indonesia sendiri memiliki potensi yang besar di bidang ekonomi digital. Survei menunjukkan proporsi ecommerce setiap sebulan sekali tumbuh lebih dari $60 \%$ pada 2017, meningkat dari sekitar 30\% pada 2016 [2].

Kota Tegal yang pernah disebut sebagai Jepang nya Indonesia, memiliki jumlah IKM (Industri Kecil Menengah) sebanyak 1163 IKM besar dan kecil yang tersebar di 4 (empat) wilayah Kecamatan dan berbagai produksi mulai dari industri logam, kuliner, konveksi, kerajinan tangan, alat olah raga, alat transportasi, fashion dan masih banyak lagi serta menyerap sebesar 6.480 pekerja. Data tersebut diperoleh dari pendataan yang dilakukan Dinas Perindustrian dan Perdagangan Kota Tegal pada Tahun 2013.

Dari sekian banyak IKM yang ada di Kota Tegal hampir seluruh produk dari IKM dipasarkan melalui transaksi klasik atau model transaksi konvensional, masih banyak produsen yang belum bisa mempromosikan sekaligus memasarkan produknya secara online dikarenakan keterbatasan pengetahuan yang dimiliki oleh para pengelola usaha tersebut tentang pemanfaatan teknologi informasi khususnya internet. Hal tersebut menyebabkan para produsen secara sadar atau tidak sadar melewatkan kesempatan market share yang begitu besar dan terus berkembang dari pasar online. Secara tidak langsung bisa dikatakan para pemilik IKM di Kota Tegal belum dapat memaksimalkan pemanfaatan teknologi informasi dalam berbisnis secara online. Atau biasa disebut dengan e-commerce.

E-commerce merupakan salah satu cari bagi konsumen untuk dapat membeli barang yang dibutuhkan dengan memanfaatkan teknologi internet. Hasil yang diperoleh dari pemanfaatan teknologi e-commerce dapat dirasakan oleh kosumen individu (B-to-C) maupun pala pelaku bisnis (B-to-B) [3] . "E-Commerce tak saja menawarkan kemudahan, tetapi juga efisiensi waktu, tenaga, dan biaya" [4].

Artinya internet dengan melalui media seperti website mampu melakukan tugas sebagai penghubung antara pelaku bisnis dengan konsumen maupun antara pelaku bisnis dengan pelaku bisnis yang lain. Berdasarkan survey [5] yang telah dilakukan di sebelas kota di Indonesia, pengguna Televisi (96\%), Media Luar Ruang (53\%), Internet (44\%), Radio (37\%), Koran (7\%), Tabloid serta Majalah (3\%). Dari data tersebut, internet merupakan salah satu media yang memiliki tingkat pengguna yang cukup tinggi. Sehingga, dapat dijadikan indikasi masyarakat Indonesia gemar mengakses informasi melalui media digital. Kamudian pada tahun 2017, terjadi peningkatan penggunaan akses internet hampir semua tempat.

Meningkatnya pengguna internet serta banyaknya variasi pilihan media digital membuat maraknya para pelaku industri memproduksi iklan produknya secara online. Para konsumen pun disuguhkan dengan banyaknya pilihan produk yang lebih mudah dilihat atau bahkan dibeli tanpa harus melihat produk aslinya.

Sedangkan untuk ketertarikan konsumen akan iklan online sebesar $60 \%$ dari konsumen pada rentan usia 21-49 tahun melakukan follow up dan lebih dari 30\% konsumen melakukan transaksi pembelian. Sebagian konsumen mengunjungi toko secara langung dan peluang terjadinya transaksi pembelian pun cukup besar dengan persentase $28 \%$. 
Pemanfaatan website sebagai alat bantu dalam sistem e-commerce sangat diperlukan, karena dengan media tersebut banyak keunggulan yang dimiliki, tidak hanya melakukan promosi produk jasa atau barang namun dapat pula melakukan transaksi secara lebih luas tanpa terkendala oleh masalah jarak dan waktu. Website memiliki banyak kelebihan dibandingkan media massa yang lain. Media ini demikian mudah digunakan, memiliki kecepatan tinggi dan jangkauan yang mendunia. Berkomunikasi lewat web dapat diakses sangat mudah melalui internet, kemudian memproduksi serta dengan mudah pula di distribusikan (disebarkan).

Dengan banyaknya IKM di Kota Tegal dan teknologi e-commerce yang sangat memungkinkan dapat dibangun dan dikembangkan, penggabungan keduanya dapat menjadi potensi yang sangat besar untuk bisa diterapkan dibangunnya sebuah $e$ commerce yang akan menyatukan para pelaku bisnis IKM di Kota Tegal untuk memperoleh pasar yang lebih luas dan dapat membantu para pelaku bisnis IKM memperoleh market share di pasar online yang memiliki potensi semakin luas dari tahun ke tahun. Dengan meningkatkan potensi pasar online secara langsung berdampak menjadikan produktifitas IKM meningkat dan tentunya berdampak pula perekonomian di Kota Tegal ikut meningkat dan tentunya akan berdampak positf dan ikut mendukung program pemerintah tentang ekonomi digital.

\section{Research Method}

\subsection{Metode Penelitian}

Permasalahan yang dikaji pada penelitian ini adalah membangun sebuah website ecommerce sebagai media penjualan yang dilakukan secara online bagi para pelaku industri IKM di kota Tegal. Model Waterfall merupakan salah satu model pengembangan perangkat lunak yang ada di dalam model SDLC (System Development Life Cycle)[6]. SDLC memiliki tahapan penelitian seperti pada gambar 1.[7]:

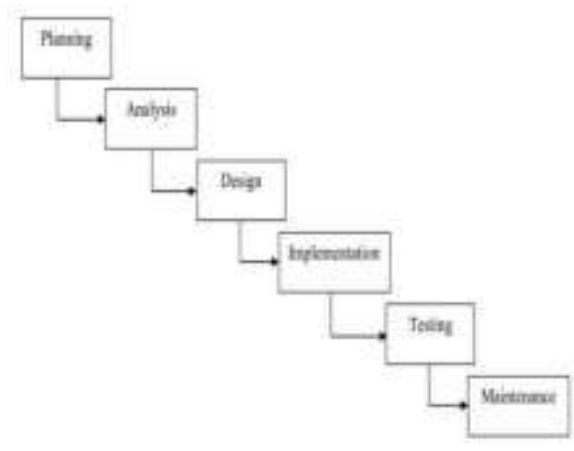

Gambar 1. Model Waterfall SDLC (System Development Life Cycle)

TRANSFORMATIKA Vol. 16, No. 1, Juli 2018: $40-52$ 
1. Planning (Perencanaan)

Tahap ini adalah tahap penentuan hal-hal penting sebagai dasar dari permasalahan yang akan dianalisis. Dalam tahap ini dilakukan identifikasi masalah, pengumpulan data, menentukan kebutuhan sistem, mengevaluasi berbagai solusi alternatif dan melakukan verifikasi data. Data - data yang dibutuhkan diperoleh dari para pelaku IKM seperti foto produk, harga produk, spesifikasi dan sebagainya yang kesemuanya memuat informasi tentang produk yang akan dipasarkan. Kemudian mempersiapkan komputer sebagai alat utama yang didalamnya sudah terinstal aplikasi yang dibutuhkan dalam membangun halaman website seperti Sublime Text, Adobe Dreamweaver, MySQL, Adobe Photoshop dan beberapa aplikasi pendukung.

\section{Analysis (analisis)}

Pada tahap ini ditentukan model data yang akan digunakan dan model proses yang akan diterapkan. Pada tahap ini juga nantinya akan ditelaah lebih lanjut aspek-aspek keuntungan, tantangan dan peluang dalam menerapkan website toko daring IKM Kota Tegal. Data - data produk dari IKM yang beragam jenis dan bentuknya perlu melalui proses sortir, produk produk mana saja yang memungkinkan proses penjualannya dapat dilakukan secara online. Produk dari IKM dilihat dan diamati dari jenis produk, berat produk, dimensi produk dan hal hal lain yang dapat memberikan pertimbangan sebuah produk memungkinkan dijual secara online terutama dari aspek kemudahan pengiriman, masa kadaluarsa, biaya pengiriman dan ketahanan produk.

\section{Design (Desain)}

Tahap ini merupakan suatu proses menginventarisir dan mengubah kebutuhan-kebutuhan menjadi bentuk karakteristik yang dimengerti oleh perangkat lunak sebelum pembuatan website toko daring IKM Kota Tegal. Desain ini akan dijadikan sebuah parameter dalam pembuatan website toko daring IKM Kota Tegal, dengan mempertimbangkan faktor kemudahan pengguna, antar muka yang menarik dan ringan untuk diakses secara online.

\section{Implementation (Implementasi)}

Pada tahap implementasi kegiatan yang dilakukan adalah dengan menulis pengetahuan yang telah direpresentasikan (disandikan) dengan bahasa pemrograman web, instalasi, demonstrasi dan penerapan sistem, orientasi pemakai, keamanan, dokumentasi dan integrasi yang kesemuanya nanti melalui proses uji coba.

\section{Testing (Uji Coba)}

Setelah tahapan implementasi selesai dikerjakan, tahap selanjutnya adalah dengan melakukan pengujian hasil implementasi, yaitu dengan melakukan pengujian terhadap website Toko Daring IKM Kota Tegal dengan cara mengoperasikan, melakukan file hosting, mengintegrasikan sistem serta melakukan updating dan entry data produk-produk IKM yang akan dipasarkan pada website toko daring tersebut. Serta melakukan pengujian pengguna (usability testing).

Usability merupakan penilaian seorang user tentang sejauh mana suatu produk tersebut dapat mencapai target yang ditetapkan dengan efektivitas, efesiensi, kepuasan penggunaan, serta terdapat tidaknya kesalahan pada sistem. Alasan sebuah tampilan website perlu diukur adalah untuk mengetahui kualitas situs tersebut dari sisi pengguna. Apakah laman tersebut sesuai dengan standarisasi yang dikeluarkan oleh Kementrian Komunikasi Republik Indonesia tahun 2003. [8]. Aspek-aspek dalam usability testing ini mencakup lima hal, yaitu [9]: Learnability, Efficiency, Memorability, Errors, dan Satisfaction.

Upaya Peningkatan Pendapatan Industri Kecil Menengah Dengan Pembuatan Toko Daring Berbasis Framework Codeigniter (Very Kurnia Bakti) 
Penentuan besar sample usability testing ditentukan dengan menggunakan rumus Slovin, yaitu [10]:

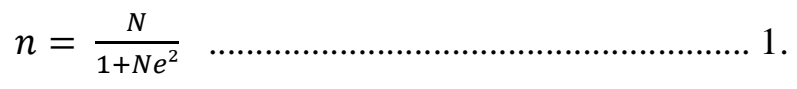

Keterangan:

$\mathrm{n}=$ jumlah sampel

$\mathrm{N}=$ jumlah populasi

$\mathrm{e}=$ batas toleransi kesalahan : $5 \%$.

Pada pengujian ini, pemilihan sampel dilakukan secara acak. Batas toleransi kesalahan sebesar 5\%. Jumlah populasi pelaku IKM yang dikelola DISPERINDAG adalah 20 anggota, maka jumlah sampel yang digunakan dalam pengujian adalah:

$$
\begin{aligned}
& n=\frac{20}{1+\left(20 \times 0,05^{2}\right)} \\
& n=19 \text { orang }
\end{aligned}
$$

2.2. Rancangan Penelitian

Adapun Rancangan penelitian yang akan dilakukan adalah seperti pada gambar 2.

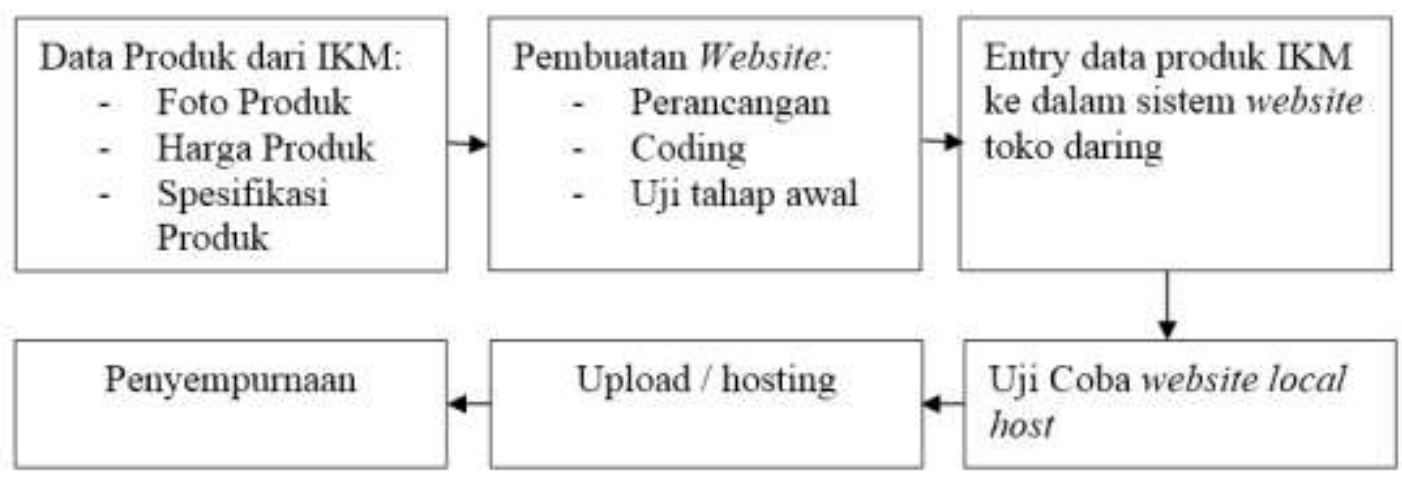

Gambar 2. Rancangan Penelitian

\subsection{Teknik Pengumpulan Data}

Dalam penelitian yang akan dilakukan dibutuhkan data - data yang nantinya diperlukan dalam membangun toko daring, teknik pengumpulan data dengan cara wawancara langsung dengan pengelola IKM untuk memperoleh informasi detail tentang produk yang dihasilkan dan pengambilan foto - foto produk yang siap dijual, foto - foto tersebut akan menjadi visual produk dalam halaman toko daring.

\section{Hasil dan Analisa}

Pengujian yang dilakukan dalam penelitian ini menggunakan usability testing. Dengan memberikan sejumlah task yang telah dipersiapkan sebelumnya kepada setiap user dengan sistem yang akan diuji. Task ini diberikan kepada 19 sample acak dari user, meliputi : super admin, pelaku ikm, serta calon pembeli. Task-task tersebut digunakan sebagai 'sarana interaksi' dalam pengukuran usability [11].

TRANSFORMATIKA Vol. 16, No. 1, Juli 2018: $40-52$ 


\subsection{Hasil Perancangan}

\section{A. Perancangan Sistem}

Solusi yang dilakukan pada tahap ini membuat desain perancangan sistem dengan menggunakan use case diagram. Use case diagram merupakan pemodelan untuk perlakuan aktor (behavior) pada sistem informasi yang akan dibuat [12]. Use case juga digunakan menganalisis kebutuhan fungsional sistem .Diagram use case terdiri atas actor, use case, asosiasi, dan dependensi dari sistem.

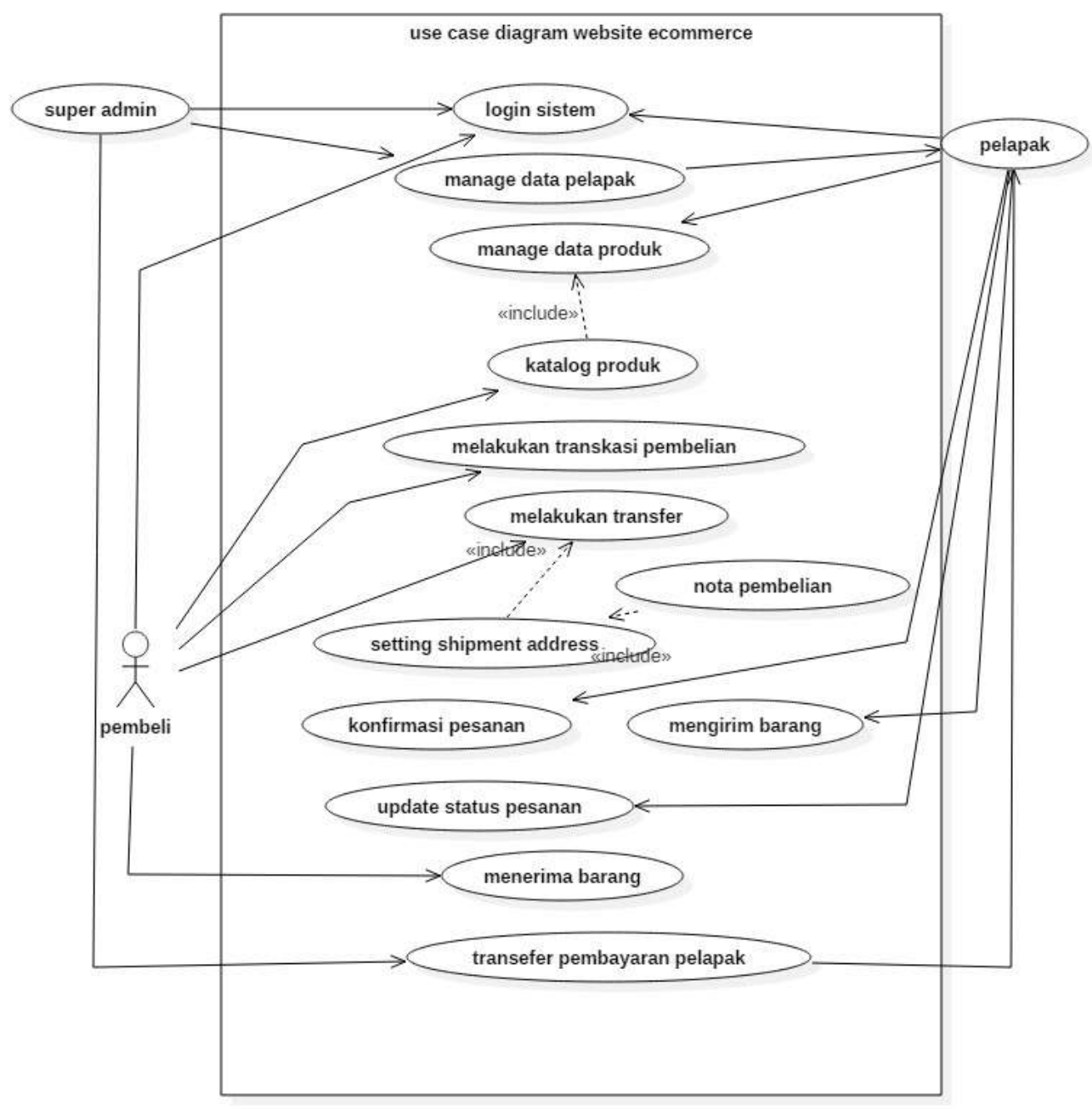

Gambar 3. Use Case Diagram Sistem

Gambar 3 menjelaskan alur dari sistem yang dibangun dimulai dari super admin melakukan login kemudian mengelola data pelapak yang nantinya akun tersebut digunakan pelapak untuk mengelola tokonya. Super admin juga dapat memanage tampilan website. Untuk mengelola produk seorang admin harus melakukan login terlebih dahulu kemudian melakukan kelola produk yang nantinya tampil dihalaman katalog. Untuk melakukan transksi barang seorang pembeli diwajibkan memiliki akun, setelah memilih barang pada katalog, pembeli melakukan transfer kemudian 
mengisi isian pada laman shipment address. Selanjutnya user akan menerima status barangnya dari konfirmasi produk hingga menerima tracking posisi barang. Setelah transaksi sukses pelapak dapat menerima hasil dari pembelian yang akan ditransfer oleh akun super admin dalam jangka waktu yang disepakati.

\section{B. User Interface}

Pembuatan user interface bertujuan untuk menjadikan teknologi informasi tersebut mudah digunakan oleh pengguna atau disebut dengan istilah user friendly [13]. Dalam pembuatan website ecommerce dihasilkan sebuah sistem dengan tampilan sebagai berikut :

1. Halaman Utama

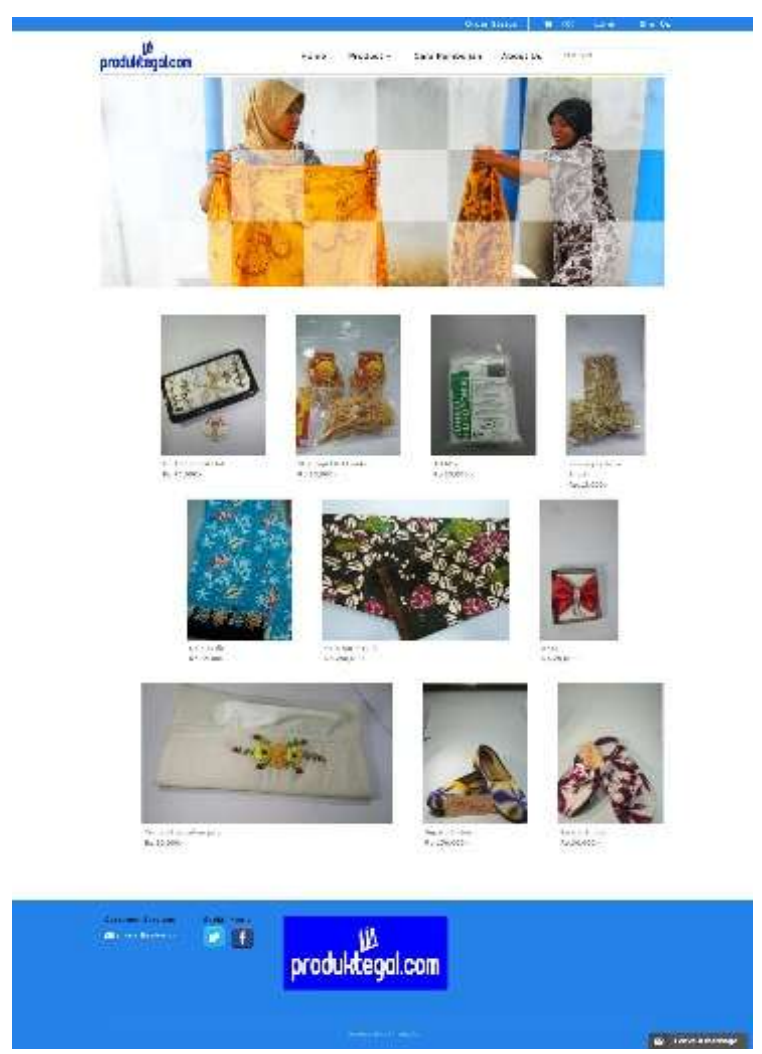

Gambar 4. Halaman Home

Halaman tersebut merupakan halaman yang pertama kali diakses oleh pembeli, halaman tersebut menampilkan katalog barang yang dijual oleh para pelaku IKM.

TRANSFORMATIKA Vol. 16, No. 1, Juli 2018: $40-52$ 
2. Halaman Detail Produk

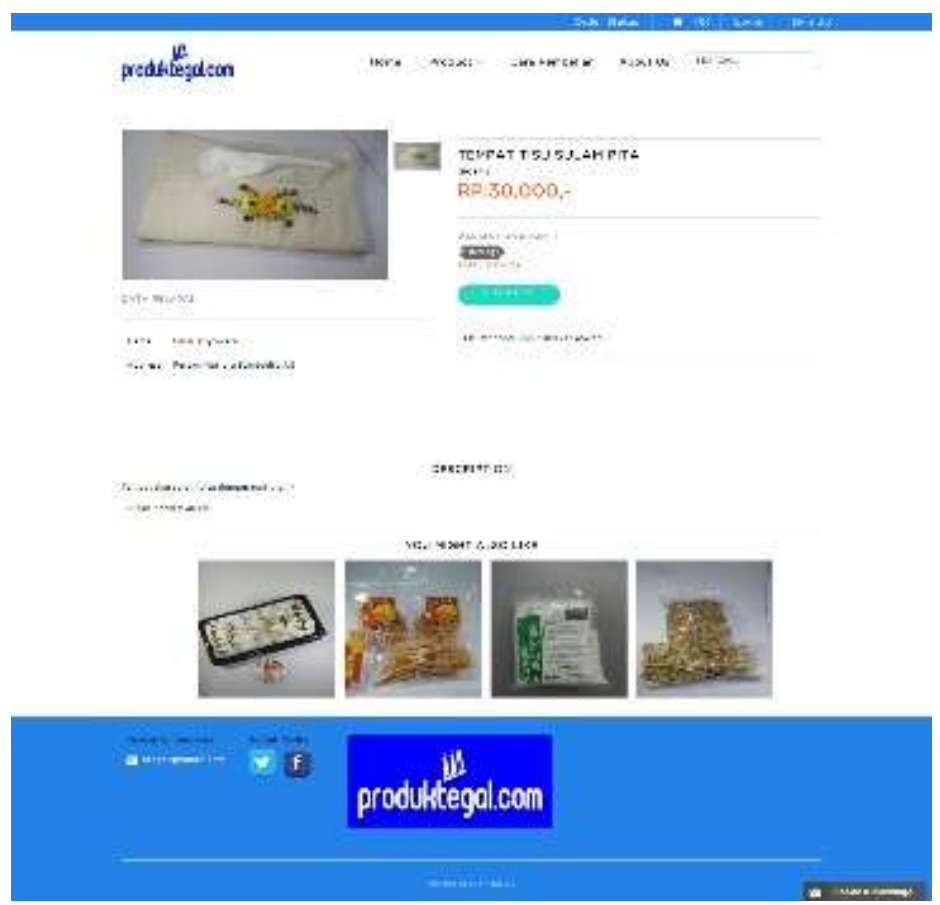

Gambar 5. Detail Produk

Tampilan tersebut menampilkan detail informasi dari barang yang dijual, dilengkapi dengan menu zooming foto produk.

3. Halaman Shoping Chart

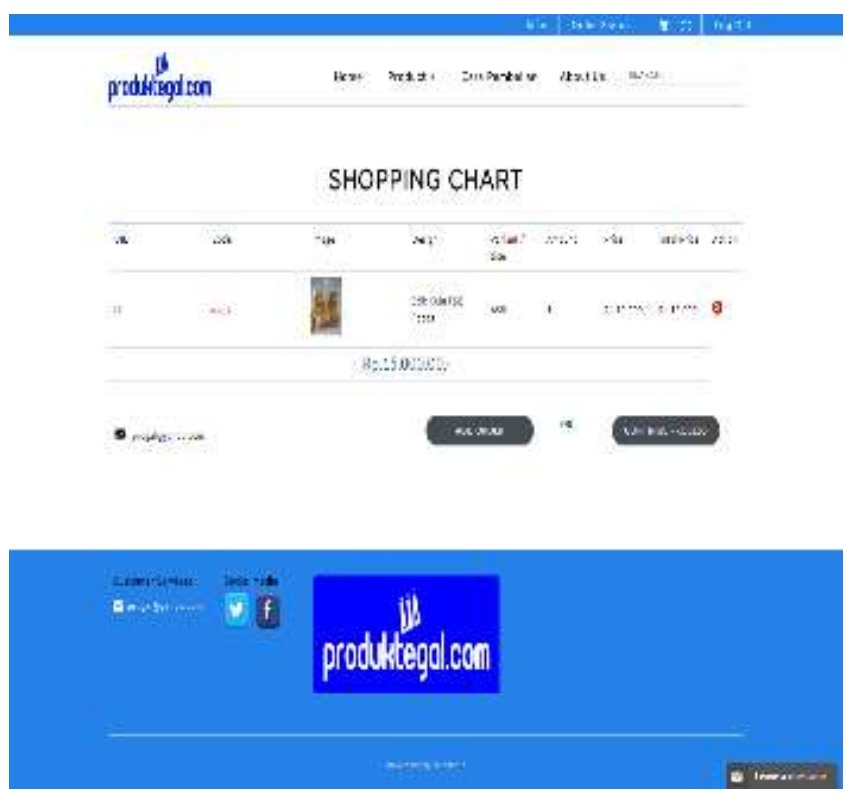

Gambar 6. Halaman Shoping Chart 
Merupakan halaman yang menampilkan keranjang serta manage daftar belanja dilengkapi detail harga barang.

4. Halaman Register Or Sign Up

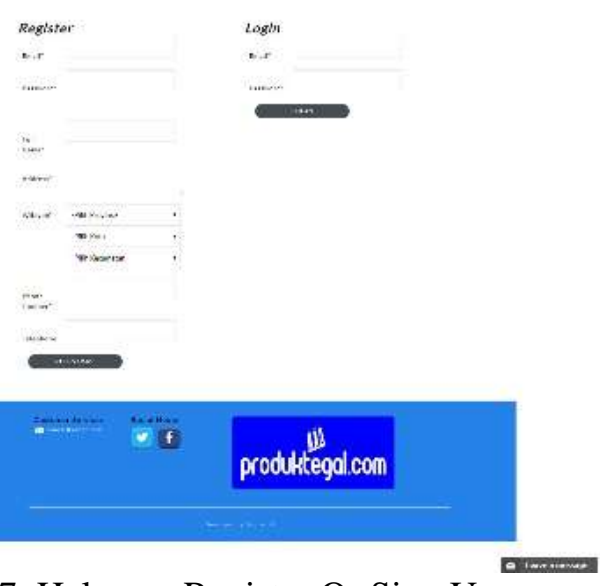

Gambar 7. Halaman Register Or Sign Up

Sebelum melanjutkan ke proses pembayaran pembeli harus memiliki akun terlebih dahulu. Terdapat dua pilihan untuk yang telah memili akun maupun untuk mendaftar akun.

5. Halaman Shiping Address

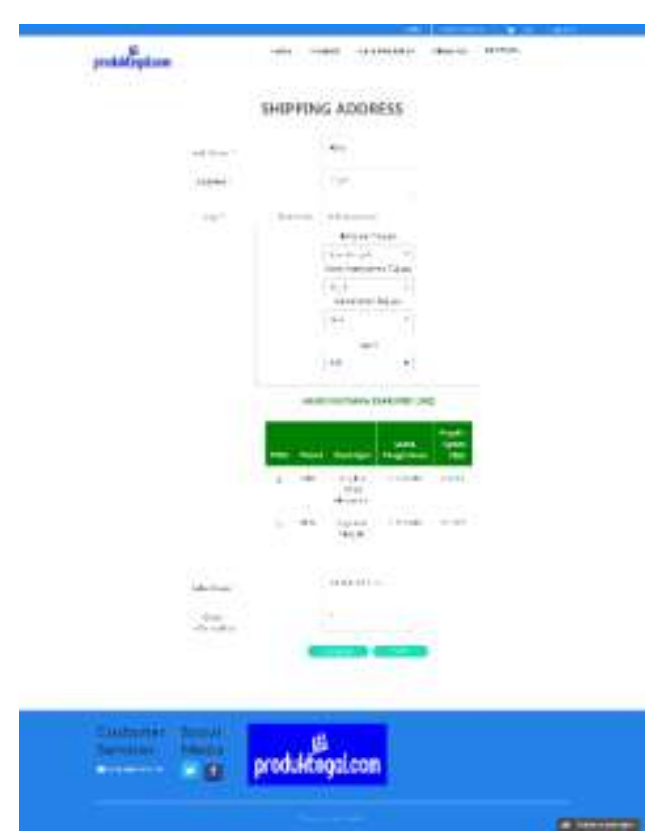

Gambar 8. Halaman Shopping Address

Dihalaman ini pembeli diwajibkan mengisi alamat pengiriman. Harga serta paket ongkos kiriman dilengkapi oleh sistem API pengiriman yang realtime.

TRANSFORMATIKA Vol. 16, No. 1, Juli 2018: $40-52$ 
6. Status Transaksi

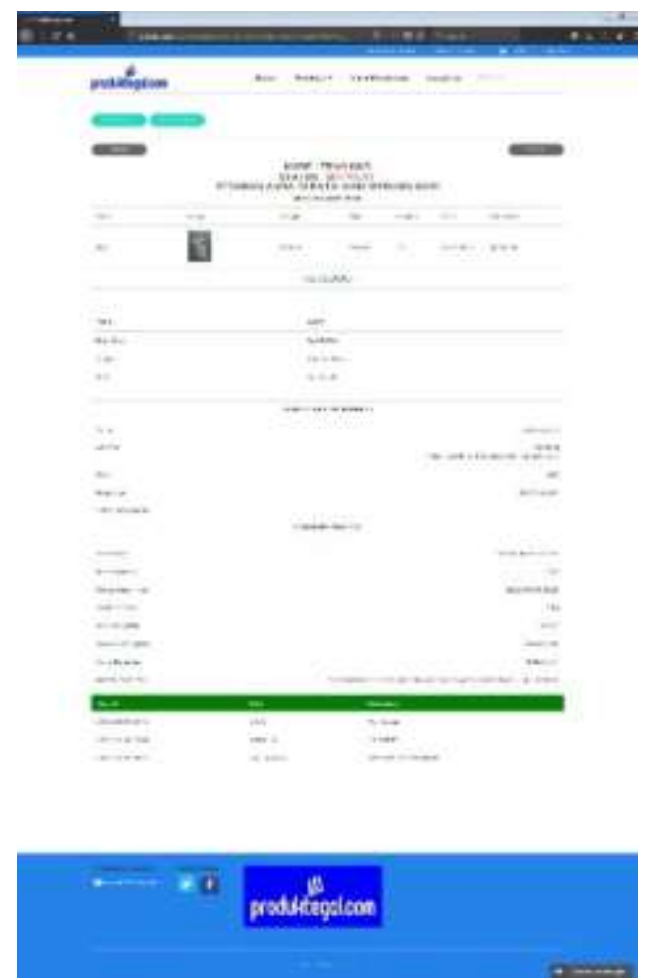

Gambar 9. Halaman Status Transaksi

Menampilkan status barang maupun status pengiriman barang. User dapat melihat barang yang dibeli sudah diproses sampai diproses apa, atau barang yang dikirim telah sampai dimana.

7. Dashboard Admin

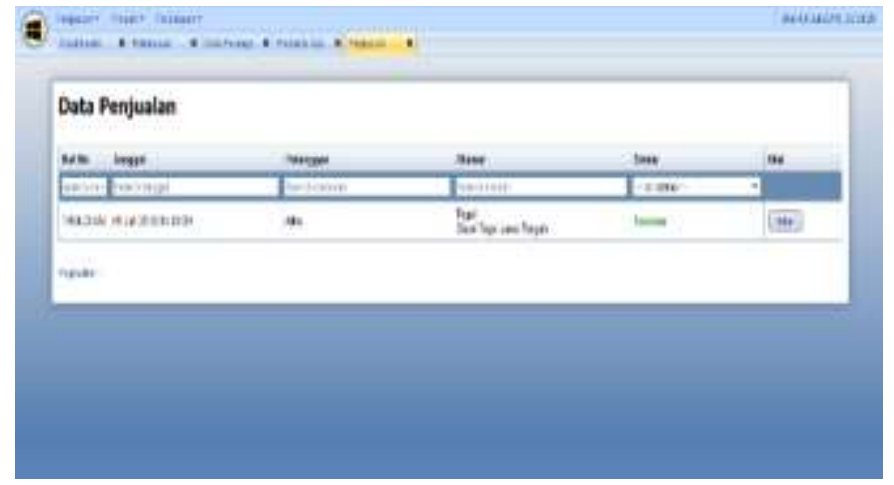

Gambar 10. Halaman Dashboard Admin

Halaman tersebut merupakan halaman yang dikases pelapak untuk mengelola produknya, stok barang, varian, serta penerimaan pelunasan. Serta terdapat menu pendukung lainnya seperti akun admin. 


\section{Dashboard Super Admin}

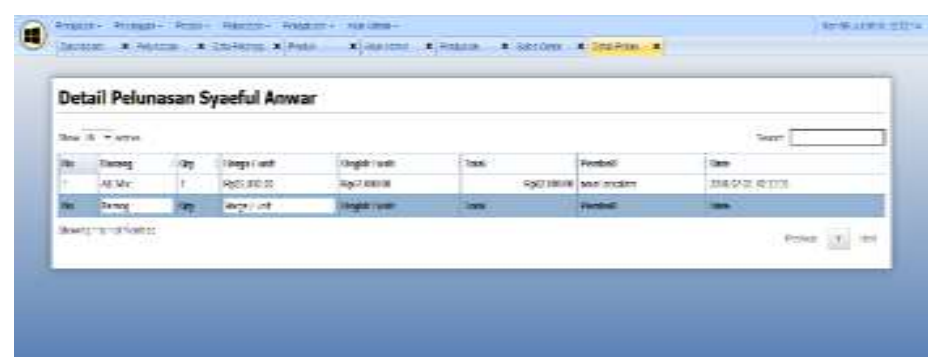

Gambar 11. Halaman Dashboard Super Admin

Merupakan halaman yang dikases oleh super admin untuk memanage para pelapak, tampilan website maupun pelunasan kepada pelapak.

\subsection{Hasil Pengujian}

Berikut ini merupakan daftar task serta hasil nilai yang diujikan :

Tabel 1. Task Uji Usability User

\begin{tabular}{|c|c|c|}
\hline NO & Kriteria & Nilai \\
\hline 1. & $\begin{array}{l}\text { Saya rasa tampilan menu dalam aplikasi mudah } \\
\text { dikenali }\end{array}$ & 4,63 \\
\hline 2. & Saya rasa simbol-simbol gambar mudah dipahami & 4,31 \\
\hline 3. & $\begin{array}{l}\text { Saya pikir orang-orang akan sangat cepat bisa } \\
\text { menggunakan aplikasi ini }\end{array}$ & 4,05 \\
\hline 4. & $\begin{array}{l}\text { Warna - warna yang ada dalam aplikasi ini, } \\
\text { tidak mencolok dan tidak merusak tampilan. }\end{array}$ & 4,11 \\
\hline 5. & $\begin{array}{l}\text { Saya melihat ada bagian fitur aplikasi ini yang } \\
\text { cukup merepotkan, yang mestinya hal itu tidak } \\
\text { perlu terjadi }\end{array}$ & 3,79 \\
\hline 6. & Saya rasa aplikasi ini mudah digunakan & 4,16 \\
\hline 7. & $\begin{array}{l}\text { Mudah dalam mengakses informasi } \\
\text { produk yang ditawarkan }\end{array}$ & 4,05 \\
\hline 8. & $\begin{array}{l}\text { Apakah aplikasi transaksi pembayaran yang } \\
\text { tersedia mudah } \\
\text { Diakses? }\end{array}$ & 3,68 \\
\hline 9. & $\begin{array}{l}\text { Apakah spesifikasi produk yang ditawarkan } \\
\text { sesuai dengan kebutuhan? }\end{array}$ & 4,05 \\
\hline
\end{tabular}

TRANSFORMATIKA Vol. 16, No. 1, Juli 2018: $40-52$ 


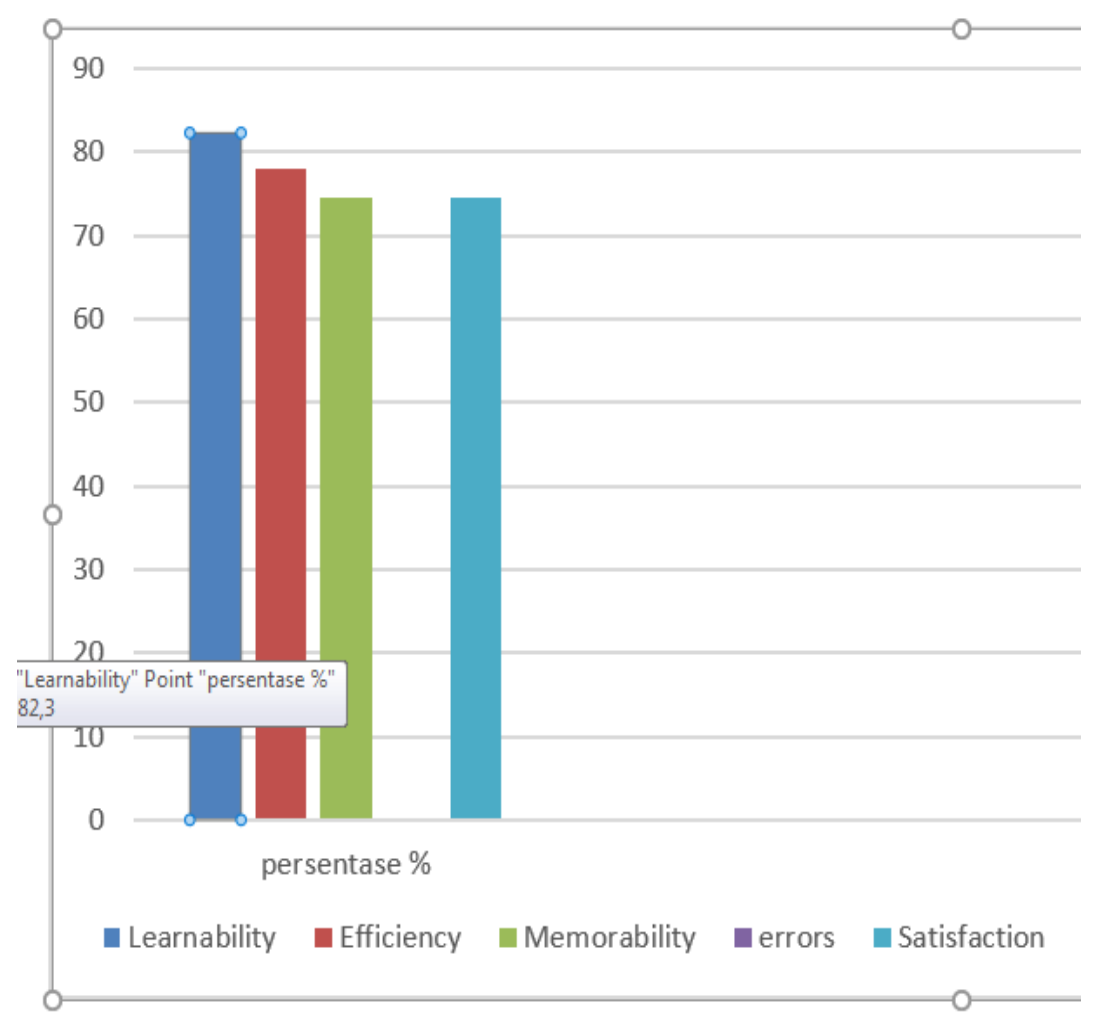

Gambar 12. Persentase Aspek Usability Testing

Gambar 12 diatas mengambarkan hasil tiap aspek usability testing, dari hasil pengujian didapati perolehan learnability sebesar $82,3 \%$, efficiency $78 \%$, memorability sebesar 74,5\%, perolehan error $0 \%$ serta satisfaction $74,6 \%$.

\section{Kesimpulan}

Hasil yang diperoleh dari pengujian usability testing memiliki nilai penerimaan rata-rata sebesar 4,09. Dari hasil tersebut menunjukan aplikasi yang dibuat dapat diterima dan dipahami dengan baik oleh pengguna.

\section{References}

[1] Arie C, Pikiran Rakyat. "Manfaat Inovasi Teknologi Dibahas ASEAN-US Summit". 14 Desember 2017 . http://www.pikiran-rakyat.com/luar-negeri/2016/02/16/361124/manfaatinovasi-teknologi-dibahas-asean-us-summit.

[2] Agnes Savithri, CNN Indonesia. "Sektor E-Commerce Tumbuh, Tokopedia Merajai Pasar Indonesia". 20 Maret 2018. https://www.cnnindonesia.com/teknologi/20180221105010-185277674/sektor-e-commerce-tumbuh-tokopedia-merajai-pasar-indonesia.

[3] Hani A.M, et al. Pemanfaatan Web E-commerce untuk Meningkatkan Strategi Pemasaran. Jurnal Ilmu Komputer dan Informatika. ISSN: 2477-698X. 2017; 3(1).

[4] Muhammad S.A, Liputan6. "2018, Transaksi e-Commerce Indonesia Akan Capai Rp 144 Triliun". 1 Januari 2018. https://www.liputan6.com/tekno/read/3057134/2018-transaksi-ecommerce-indonesia-akan-capai-rp-144-triliun. 
[5] Ilmuonedata. "Top Performing Online Consumer Goods Retailer In Indonesia”. Maret 2018. http://www.ilmuonedata.com.

[6] Yoki A, Udi. Penerapan Metode SDLC Waterfall Dalam Pembuatan Sistem Informasi Akademik Berbasis Web Studi Kasus Pondok Pesantren Al-Habi Sholeh Kabupaten Kubu Raya, Kalimantan Barat. Jurnal Teknologi \& Manajemen Informatika. 2018; 4(1): 2.

[7] Blanchard, B. S., \& Fabrycky, W. J. Systems engineering and analysis (4th ed.). New Jersey: Prentice Hall. 2006.

[8] Wibowo DS. Usability Testing Sistem Pada E-Academic Politeknik Harapan Bersama. Jurnal Teknik Elektro. ISSN 1411-8890. 2016; 16(1):1.

[9] ISO. "Ergonomic Requirement For Office Work With Visual Display Terminals (VDTs) Part 11 : Guidance On Usability". Maret 2018 . https://www.iso.org/standard/16883.html .

[10] Delfi A., et al. Manajemen Pengetahuan Melalui Web 2.0 (Wikipedia) pada Organisasi Studi Kasus: Himpunan Mahasiswa di Kampus XXX. Jurnal Infotel. ISSN 2460-0997.2017; 9(3).

[11] Sastramihardja, H., et al. Pengukuran Usability Dengan Sarana Task Model Dalam User Center Software Development. Jurnal Penelitian dan Pengembangan Telekomunikasi. 2008; $13(2)$.

[12] Ade H. Pemodelan Uml Sistem Informasi Monitoring Penjualan Dan Stok Barang (Studi Kasus: Distro Zhezha Pontianak). Jurnal Khatulistiwa Informatika. 2016; 4(2).

[13] Alfian N., et al. "Analisis Pengaruh User Interface Terhadap Kemudahan Penggunaan Sistem Pendukung Keputusan Seorang Dokter”. Prosiding SNATIF Ke-1. ISBN: 978-6021180-04-4. 2014. 